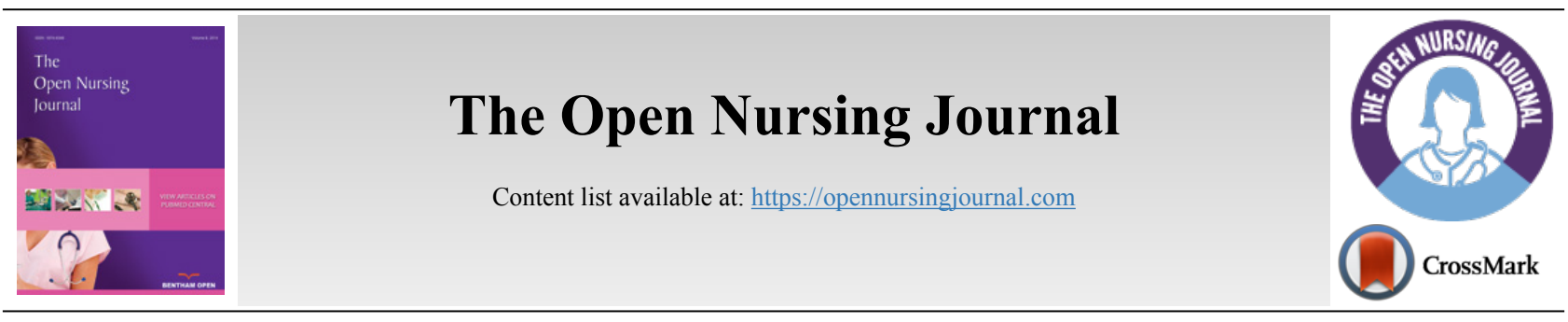

RESEARCH ARTICLE

\title{
Effects of a Standardized Care Protocol for Patients with Degenerative Spine Disease
}

\author{
Hwa-Jung $\operatorname{Lim}^{1}$ and Bo-Yeoul Kim ${ }^{2, *}$ \\ ${ }^{1}$ Anesthesiology Department, Daejeon Medical Center, Eulji University, Daejeon, Korea \\ ${ }^{2}$ College of Nursing, Eulji University, Daejeon, Korea
}

\begin{abstract}
:
Background:

Many patients facing spinal surgery experience fear and anxiety about surgery, anesthesia, risk of postoperative pain or complications, or even death. Spinal surgery patients often experience mobility disorders due to lasting postoperative pain and require aids such as spinal braces, which can induce depression. Alleviating patients' anxiety and depression during the perioperative period by utilizing consistent and standardized information is required for high-quality care.

\section{Objective:}

We developed and assessed a standardized care protocol for degenerative spinal surgery patients.

Methods:

The protocol was developed through focus group interviews with spinal surgery patients and the recommendations of an expert panel. Then, a quasi-experimental design was employed to comparatively study patients undergoing spinal surgery. Ninety-eight Patients were assigned to either a treatment group $(n=49)$ or a control group $(n=49)$. The treatment group received an intervention based on the newly developed standardized care protocol, while the control group received traditional care. After treatment, participants' anxiety, depression, uncertainty, and care satisfaction were compared between groups.

Results:

Patients who had received the care protocol-based intervention showed lower anxiety, depression, and uncertainty, and higher satisfaction than did those who received traditional care.

\section{Conclusion:}

The developed care protocol may be useful for reducing anxiety and depression and for improving the healthcare provided to spinal surgery patients, as it involves the proactive dissemination of accurate information throughout the hospitalization process. The protocol also positively affected patients' uncertainty and satisfaction with their medical care.
\end{abstract}

Keywords: Education, Nursing, Perioperative Care, Spine, General Surgery, Anxiety, Depression, Hospitalization.

\begin{tabular}{l|l|l|l} 
Article History & Received: November 11, 2018 & Revised: December 19, 2018 & Accepted: December 28, 2018
\end{tabular}

\section{INTRODUCTION}

Degenerative diseases, which require various surgical treatments, are common in adults aged 50 years or older. Spinal diseases are the most prevalent musculoskeletal and skeletal degenerative disorders [1]. In recent decades, degenerative

Address correspondence to this author at College of Nursing, Eulji University, 77 Geryong-ro, 771 Beon-gil, Jung-gu, 34824 Daejeon, Korea;

Tel: 82-2-10-5437-1882; Fax: 82-42-259-1709;

E-mail: goddess11@naver.com spinal disease has led to a dramatic increase in the need for surgical treatment $[2,3]$. In 2014, nearly 12.6 million people were treated for spinal diseases, and 1 out of 4 Koreans experienced spine-related symptoms [4]. Spinal surgery is one of the most common surgeries in the United States [5]. As the number of spinal surgery cases increases, the costs associated with treating spinal diseases also increase [2].

Spinal surgery patients expect the surgery to improve their quality of life [5]. However, these patients may experience fear 
and anxiety due to uncertainty about the surgery, anesthesia, postoperative pain or complications, and the possibility of death $[6,7]$. Physical functions and pain after surgery are linked to patients' pre-operative physical condition and emotional stress; severe prior anxiety and depression can negatively affect one's physical function and pain after surgery [8].

Mobility is a key physiological factor that affects the decision to discharge a patient from the hospital [9]. Spinal surgery patients often experience mobility disorders from pain that persists after surgery and require aids [9]; further, they often experience anxiety and depression because of the residual pain or discomfort they experience after surgery [10]. However, providing information regarding the surgery process can have a significant mediating effect on surgical patients' anxiety and depression [11]. Patients can only begin to cope with their situation after they fully understand it and being informed allows them to adjust their expectations regarding resuming activities after surgery [12]. A study of patients with lumbar surgery revealed that information provision could be a mediating factor in improving patients' quality of life. If patients' physical function after pain improves and information about what the patient will experience during the surgical process is provided, they usually report a high quality of life before the surgery, although their actual quality of life was low $[5]$.

Additionally, to receiving practical help, patients must receive information about the uncertainty of their situations. They also desire opportunities to communicate with their doctors [13]. However, in clinical practice, there is less communication between patients and medical staff than required [14]. To ensure that spinal surgery patients do not experience anxiety and depression due to a lack of information or uncertainty, the timely provision of useful information during the recovery process is crucial [15]. It is also important to ensure that patients have easy access to help from medical staff [16].

Prior studies found that preoperative educational interventions resulted in significant reductions in patients' preoperative anxiety $[11,17]$. Spinal surgery patients and caregivers should receive interdisciplinary, holistic care and standardized treatment with consistent education from medical staff before, during, and after surgery [18]. In clinical practice, however, treatment plans, nursing schedules, and education vary across medical staff and medical fields, which may lead to patients' confusion and suspicion. Thus, it is necessary to develop consistent, standardized guidance that can be provided by clinical teams. This will improve the quality of care provided to patients and foster their trust in medical staff. Additionally, close communication between inpatients and doctors, nurses, and caregivers is required to provide adequate care [19].

In Korea, clinical schedules have been implemented for patients with diseases requiring simple procedures, including cataract operations, tonsil and appendix removals, hernia and hemorrhoid operations, uterine surgery and cesarean sections, which are classified into diagnosis-related groups; however, this is not the case for patients with spinal diseases. We anticipate that a standardized care protocol, including care before and after surgery (from the time of admission to the time of discharge), and medical-based assistance such as braces, medication, wound care, symptom management, as well as promoting activities of daily living and exercise will provide patients with high-quality care and allow them to achieve psychological stability. Such assistance will enable patients, who must be cautious after surgery, to practice selfcare and exercise, which can improve their health management abilities and thereby improve their quality of life.

Previous literature in both Korean and international settings has investigated the effect of pre-surgical interventions (i.e., education) on patients' anxiety [11], the effect of expectations on recovery after lumbar spinal surgery [5], the factors that affect care after discharge [9], and the length of hospital stay after lumbar spine surgery [20]. Educating spinal surgery patients and their caregivers and promoting active patient participation are essential components of multidisciplinary clinical practice. This includes nurses' proactive assessment of complications [18], nurse's role in promoting a safe perioperative course for lumbar spinal fusion patients [21], and development of treatment-oriented pathways to reduce the length of stay as an Enhanced Recovery After Surgery program (ERAS) for elective spinal surgery patients [22].

However, ostensibly, research on clinical schedule has adopted multidisciplinary approaches, but it has actually followed the treatment plan led by surgeons. Moreover, scant research has addressed nurse-led care protocols. Further, because only partial clinical schedules were available regarding the classification of diagnosis-related groups in Korea, this study developed a standardized care protocol with an emphasis on the nursing care. Our specific purpose was to develop and implement a standardized care protocol for patients undergoing degenerative spinal surgery and to identify its impact on patients' psychological well-being. We hypothesized that our protocol would significantly decrease patients' depression, anxiety, and uncertainty, and improve their care satisfaction.

\section{MATERIALS AND METHODS}

\subsection{Research Design}

This quasi-experimental study used a nonequivalent control group with a timelag design.

\subsection{Data}

The primary outcomes were patients' anxiety and depression post-surgery but before discharge. Secondary outcomes were patients' uncertainty and care satisfaction. G*Power analysis software was used to calculate the optimal sample size for this study: At $p<.05$, to have $85 \%$ power and detect an effect size of 0.6 , the optimal sample size was 41 individuals per group. With an estimated potential drop-out rate of $20 \%$ [23], the optimal sample size increased to 51 patients per group $(n=$ 102). 


\subsubsection{Participant Selection}

The following inclusion criteria were applied: 1) adult patients aged $>50$ years diagnosed with spinal disease and treated at Eulji University Hospital; 2) individuals without a psychiatric or cognitive impairment; 3 ) individuals without any problems reading, speaking, or writing in Korean; 4) spinal surgery patients undergoing decompression, fusion, anterior spinal fusion, spondylotomy, discectomy, or fixation; and 5) individuals who understood the purpose of this research and voluntarily agreed to participate.

The following exclusion criteria were applied: 1) individuals who were participating in another intervention program; 2) individuals with a diagnosed psychiatric illness, such as depression or cognitive impairment anamnesis; 3) patients who were transferred to other wards; 4) patients with fever, pneumonia, or complications in the surgical ward before surgery; and 5) patients who previously underwent surgery or for whom surgery was urgent.

\subsection{Protocol Development Process}

Protocols are organized ways of analyzing and managing major symptoms or disease progressions. They are more specific, procedure-oriented, and pertinent to a group of patients [24]. They contain the definition of a problem or background information, subjective and objective data, information for the education of the patient and family, and future care plans [24].

\subsubsection{Preliminary Protocol Development}

\subsubsection{Literature Review and Analysis of Medical Records}

To develop a preliminary protocol, we conducted an indepth literature review and collected relevant educational materials before analyzing data from the medical records of patients $(n=51)$ who underwent spinal surgery at Eulji University Hospital. This took place between March 1 and July 31,2017 . The data analysis portion of the study was performed between August 1 and 31, 2017, and was based on doctors' order records, medication records, nurses' records, and nursing activity records. The entirety of nursing care performed from the day of admission to discharge was analyzed using frequencies and percentages.

Based on the results of the initial data analysis, the medical records featuring work items with a frequency or percentage of $\geq 80 \%$ were included. The analysis excluded the medical records of patients who (1) underwent emergency surgery; (2) were rated class 2 or higher on the American Society of Anesthesiologist's pre-anesthesia evaluation; (3) aside from the spinal surgery, had undergone surgery for other complications; (4) had undergone re-operation; and (5) required care in the intensive care unit.

\subsubsection{Basic Protocol Format}

Eight categories of interest "care", "treatment", "examination", "diet", "medication", "activity", "education", and "explanation" were identified through the literature review process; these categories were then evaluated by an expert panel who were asked to reach consensus regarding the categories to be included in the final protocol. The final categorized items "care and treatment", "examination", "diet", "medication", "activity," and "education and explanation" were determined based on frequency in everyday care.

\subsubsection{Expert Content Validity}

Based on the recommendations presented by Lynn [25], two eight-member expert panels were organized to verify the protocol (content validity index $\geq .80$ ). The first content validity test included the analyzed medical records. The outputs were used to revise and supplement the protocol by referencing the assessment criteria tool developed by Kang, Yoo, and Ko [26] and considering the feedback of the expert panel. The attributes of each subheading of the protocol were included to improve their usefulness. The main protocol was completed after the content was reviewed by the expert panel and subsequently underwent one further revision process.

\subsubsection{Focus Group Interview and Expert Panel}

Focus group interviews were conducted between August 28 and September 1, 2017, with nine randomly selected patients who underwent spinal surgery at Eulji University Hospital. Participant's responses were analyzed, and the findings were summarized using frequencies and percentages. The expert panel that reviewed and refined the protocol was a multidisciplinary team consisting of a surgeon, a nursing professor, three residents, three nurses specializing in surgery, orthopedic and anesthesiology healthcare providers, and physicians' assistants.

\subsubsection{Trial Implementation}

To test the protocol and identify any practical issues, we ran a four-week trial of the protocol with 15 patients between January 29 and February 23, 2018. During the trial, the care protocol was revised, and pictures were added to increase patient understanding. These revisions took place at regular monthly meetings, which were held to evaluate the progress and performance of the protocol. The finalized version of the care protocol was rolled out on March 14, 2018.

\subsubsection{Development and Application of Main Protocol}

After two rounds of expert revision and modification, a standardized care protocol was developed for patients who underwent spinal surgery. Appendix A shows the care protocol. The rows represent six items: care and treatment, examination, diet, medication, activity, education, and explanation. The columns represent the day before surgery (day of admission), 1-2 days after surgery (before/after), 3-5 days after surgery, 6-7 days after surgery, and 8 days after surgery-discharge. The care protocol was presented on the front page of a booklet (Appendix B), which was an integrated educational resource that was complimentary for the patients and that contained a detailed explanation of the care protocol. Nurses in the orthopedic ward of the university hospital were instructed to follow the final protocol during a two-week period (March 
14-28, 2018).

\subsection{Protocol Intervention}

\subsubsection{Treatment Group}

Education and information about the standardized care protocol were provided to patients for approximately 20 minutes in a separate education room in the ward on the day of admission. The care protocol included information about the entire hospitalization process, including preoperative preparation and postoperative care, as well as diet, medication, treatment, examination, surgical injury management, prevention of bedsores, ways to prevent getting hurt from falling, wearing a brace, activity range and movement, and spinal structure and pathogenesis. Patients were provided with instructions on how to use the protocol so that they could communicate effectively with medical staff and obtain consistent information.

\subsubsection{Control Group}

Patients who were assigned to the control group received conventional care, which may have included mixed or fragmented messages and received inconsistent information from the medical team. Moreover, information was provided orally, without any assistance manual or documents, making it difficult to access care systematically. Education and information about conventional care were provided verbally for approximately 20 minutes. All topics including care and treatment, examination, diet, medication, activity, education, and explanation other than the care protocol were consistent with those experienced by the treatment group.

\subsection{Measurement}

\subsubsection{Hospital Anxiety and Depression Scale}

To measure patients' anxiety and depression, 14 items from the Korean version of the Hospital Anxiety and Depression Scale [27] were used. Half of the items pertain to anxiety, and the other half to depression. Each item is scored using a four-point scale ( $0-3$ points); higher scores indicate higher anxiety and depression. At the time of development, the overall tool had a Cronbach's $\alpha$ of 0.86 [28]. In the Korean translation, Cronbach's $\alpha$ s were 0.89 for anxiety and 0.86 for depression [27]. In our study, Cronbach's $\alpha$ s for anxiety and depression were 0.87 and 0.74 , respectively, and the cumulative Cronbach's $\alpha$ for anxiety and depression was 0.85 . According to Snaith [29], anxiety and depression scores in the range of 0 to 7 are considered "normal," scores $8-10$ are suggestive of a mood disorder, and scores $\geq 11$ indicate a mood disorder.

\subsubsection{Uncertainty}

The Korean version of the Mishel Uncertainty in Illness Scale (MUIS) [30] was used. The tool comprises 33 questions, focusing on four sub-areas of uncertainty: 13 items concern ambiguity, 7 concern complexity, 7 concern inconsistency, 5 concern unpredictability, and 1 item is not attributed to an area. The MUIS is scored using a five-point scale ( $5=$ "strongly agree", 4 = "agree", 3 = "neutral", 2 = "disagree", and 1 = "strongly disagree"). After reverse-scoring 12 positive items, total scores range from 33 to 165 , with higher scores indicating more uncertainty. For the original MUIS [31], Cronbach's $\alpha$ ranged from .91-.93; for the Korean version [30], Cronbach's $\alpha$ was .85; and, for this study, Cronbach's $\alpha$ was .90 .

Table 1. Participants' characteristics $(n=98)$.

\begin{tabular}{|c|c|c|c|c|c|}
\hline Category & Description & $\begin{array}{l}\text { Treatment group } \\
\qquad(n=49)\end{array}$ & $\begin{array}{l}\text { Control group } \\
(n=49)\end{array}$ & $\begin{array}{c}\text { Test } \\
\text { statistic }\end{array}$ & $p$-value \\
\hline Age (years) & Mean \pm SD & $63.24 \pm 12.99$ & $63.08 \pm 11.66$ & 0.065 & .948 \\
\hline \multirow{2}{*}{$\operatorname{Sex}(n, \%)$} & Male & $15(30.6)$ & $23(46.9)$ & 2.751 & $.147^{\ddagger}$ \\
\hline & Female & $34(69.4)$ & $26(53.1)$ & & \\
\hline \multirow{2}{*}{ Spouse (n, \%) } & Yes & $39(79.6)$ & $35(71.4)$ & 5.48 & $.163^{\S}$ \\
\hline & No & $10(20.4)$ & $14(28.6)$ & & \\
\hline \multirow{5}{*}{ Religion (n, \%) } & Protestantism & $11(22.4)$ & $13(26.6)$ & 3.5 & $.481^{\S}$ \\
\hline & Buddhism & $12(24.5)$ & $16(32.7)$ & & \\
\hline & Catholic & $3(6.1)$ & $5(10)$ & & \\
\hline & None & $22(44.9)$ & $15(30.7)$ & & \\
\hline & Other & $1(2.0)$ & $0(0)$ & & \\
\hline \multirow{6}{*}{ Education (n, \%) } & None & $3(6.1)$ & $1(2.0)$ & 4.035 & $.56^{\S}$ \\
\hline & Elementary school & $12(24.5)$ & $6(12.2)$ & & \\
\hline & Middle school & $6(12.2)$ & $7(14.3)$ & & \\
\hline & High school & $7(14.3)$ & $8(16.3)$ & & \\
\hline & College or higher & $8(16.4)$ & $12(24.6)$ & & \\
\hline & No response & $13(26.5)$ & $15(30.6)$ & & \\
\hline \multirow{2}{*}{ Employed (n, \%) } & Yes & $20(40.8)$ & $25(51)$ & 1.027 & $.311^{\ddagger}$ \\
\hline & No & $29(59.2)$ & $24(49)$ & & \\
\hline
\end{tabular}


(Table 1) contd.....

\begin{tabular}{|c|c|c|c|c|c|}
\hline Category & Description & $\begin{array}{l}\text { Treatment group } \\
\qquad(n=49)\end{array}$ & $\begin{array}{l}\text { Control group } \\
\quad(n=49)\end{array}$ & $\begin{array}{c}\text { Test } \\
\text { statistic }\end{array}$ & $p$-value \\
\hline \multirow{2}{*}{ Wound infection (n, \%) } & Yes & $8(16.3)$ & $5(10.2)$ & 0.798 & $.372^{\ddagger}$ \\
\hline & No & $41(83.7)$ & $44(89.8)$ & & \\
\hline \multirow{2}{*}{ Additional administration of analgesics (n, \%) } & Yes & $27(55.1)$ & $21(42.8)$ & 1.47 & $.225^{\ddagger}$ \\
\hline & No & $22(44.9)$ & $28(57.2)$ & & \\
\hline \multirow{6}{*}{$\begin{array}{c}\text { Frequency of additional administration of } \\
\text { analgesics }(\mathbf{n}, \%)\end{array}$} & 0 & $22(44.9)$ & $28(57.2)$ & 4.413 & $.326^{\S}$ \\
\hline & 1 & $16(32.7)$ & $15(30.6)$ & & \\
\hline & 2 & $7(14.3)$ & $6(12.2)$ & & \\
\hline & 3 & $3(6.1)$ & $0(0)$ & & \\
\hline & 4 & $0(0)$ & $0(0)$ & & \\
\hline & 5 & $1(2)$ & $0(0)$ & & \\
\hline \multirow{2}{*}{ Postoperative hospital stay (days) } & Mean \pm SD & $15.19 \pm 9.02$ & $18.00 \pm 8.82$ & 1.55 & $.124^{\dagger}$ \\
\hline & Median [range] & $16[6-61]$ & $14[1-38]$ & & \\
\hline \multirow{2}{*}{$\begin{array}{c}\text { Duration of operation } \\
\text { (minutes) }\end{array}$} & Mean \pm SD & $155.1 \pm 54.26$ & $152.65 \pm 65.30$ & 0.065 & $.948^{\dagger}$ \\
\hline & Median [range] & $150[55-460]$ & $155[65-320]$ & & \\
\hline \multirow{2}{*}{$\begin{array}{l}\text { Duration of anesthesia } \\
\text { (minutes) }\end{array}$} & Mean \pm SD & $198.06 \pm 59.72$ & $192.96 \pm 69.86$ & 0.389 & $.698^{\dagger}$ \\
\hline & Median [range] & 190 [95-525] & 190 [85-380] & & \\
\hline
\end{tabular}

$p$-value obtained by an independent two-sample t-test based on the central limit theorem.

${ }^{\ddagger} p$-value based on the chi-squared test.

${ }^{\S} p$-value based on Fisher's exact test.

$S D$ : standard deviation.

Table 2. Homogeneity test of dependent variables $(n=98)$.

\begin{tabular}{|c|c|c|c|c|}
\hline \multirow{2}{*}{ Dependent variable } & $\begin{array}{l}\text { Treatment group } \\
\qquad(n=49)\end{array}$ & $\begin{array}{l}\text { Control group } \\
(n=49)\end{array}$ & \multirow{2}{*}{$\begin{array}{c}\text { Test } \\
\text { statistic }\end{array}$} & \multirow[t]{2}{*}{$p$-value } \\
\hline & $\mathbf{M} \pm \mathbf{S D}$ & $\mathbf{M} \pm \mathbf{S D}$ & & \\
\hline Anxiety & $9.76 \pm 2.60$ & $9.76 \pm 4.21$ & 0.323 & .571 \\
\hline Depression & $10.51 \pm 3.05$ & $10.16 \pm 3.61$ & 0.089 & .776 \\
\hline Uncertainty & $102.78 \pm 8.75$ & $99.29 \pm 14.85$ & 1.458 & .23 \\
\hline Care satisfaction & $41.08 \pm 6.21$ & $41.61 \pm 8.05$ & 0.005 & .944 \\
\hline
\end{tabular}

$S D$ : standard deviation.

Table 3. Between-group comparisons of dependent variables $(n=98)$.

\begin{tabular}{|c|c|c|c|c|c|}
\hline \multirow{3}{*}{ Category } & Process & $\begin{array}{c}\text { Treatment group } \\
(\boldsymbol{n}=\mathbf{4 9})\end{array}$ & $\begin{array}{c}\text { Control group } \\
(\boldsymbol{n}=\mathbf{4 9})\end{array}$ & $\begin{array}{c}\text { Test } \\
\text { statistic }\end{array}$ & $\boldsymbol{p}$-value \\
\hline \multirow{3}{*}{ Anxiety } & Pre & $9.76 \pm 2.60$ & $9.76 \pm 4.21$ & 0.323 & $.571^{\dagger}$ \\
\cline { 2 - 7 } & Post & $4.33 \pm 2.97$ & $7.82 \pm 3.97$ & 85.71 & $<.001^{\ddagger}$ \\
\cline { 2 - 7 } & Post-pre & $-5.43 \pm 2.59$ & $-1.43 \pm 1.73$ & 8.97 & $<.001$ \\
\hline \multirow{3}{*}{ Depression } & Pre & $10.51 \pm 3.05$ & $10.16 \pm 3.61$ & 0.089 & $.776^{\dagger}$ \\
\cline { 2 - 7 } & Post & $6.39 \pm 3.29$ & $8.96 \pm 3.14$ & 54.69 & $<.001^{\ddagger}$ \\
\cline { 2 - 7 } & Post-pre & $-4.12 \pm 2.20$ & $-1.20 \pm 1.73$ & 7.29 & $<.001$ \\
\hline \multirow{3}{*}{ Uncertainty } & Pre & $102.78 \pm 8.75$ & $99.29 \pm 14.85$ & 1.458 & $.23^{\dagger}$ \\
\cline { 2 - 7 } & Post & $74.35 \pm 10.96$ & $95.61 \pm 12.76$ & 193.07 & $<.001^{\ddagger}$ \\
\cline { 2 - 7 } & Post-pre & $-28.43 \pm 10.44$ & $-3.67 \pm 7.32$ & 13.59 & $<.001$ \\
\hline & Pre & $41.08 \pm 6.21$ & $41.61 \pm 8.05$ & 0.005 & $.944^{\dagger}$ \\
\cline { 2 - 7 } & Post & $52.41 \pm 5.45$ & $43.63 \pm 7.81$ & 175.39 & $<.001^{\ddagger}$ \\
\cline { 2 - 7 } & Post-pre & $11.32 \pm 4.36$ & $2.02 \pm 2.90$ & 12.44 & $<.001$ \\
\hline
\end{tabular}

${ }^{7} p$-value based on an analysis of covariance with age and sex as covariates.

${ }^{\ddagger} p$-value based on an analysis of covariance with pre-test score, age, and sex as covariates.

\subsubsection{Care Satisfaction}

To measure patients' care satisfaction, we used a 15 -item revised and supplemented version [32] of the La MonicaOberst Patient Satisfaction Scale (LOPSS) [33]. This tool is 
scored using a five-point scale (5 = "strongly agree," $4=$ "agree," 3 = "neutral," 2 = "disagree," and 1 = "strongly disagree"), and higher scores indicate higher satisfaction. For the original LOPSS, Cronbach's $\alpha$ was 0.92; for the revised version, Cronbach's $\alpha$ was 0.91 ; and, for our study, Cronbach's $\alpha$ was 0.87 .

\subsection{Data Collection}

Data were collected between December 27, 2017 and August 2, 2018 at Eulji University Hospital. A total of 98 patients with degenerative spinal disease completed a consent form and were collected without any dropouts. To prevent expansion of the intervention effect, data were first collected from the control group; then, data were collected for the treatment group in an identical manner. The data collection procedure was explained to the nursing department of Eulji University Hospital; then, we asked the professor and resident specializing in spinal surgery for their cooperation.

\subsubsection{Treatment Group}

A presurvey questionnaire that included items regarding demographics, anxiety, depression, uncertainty, and care satisfaction, was administered to patients on the day of admission. The patients or their caregivers were educated about the standardized protocol in an independent space on the day of admission. Data were collected using a post-survey completed on the day before the patients were discharged.

\subsubsection{Control Group}

As mentioned above, a presurvey questionnaire was administered to patients on the day of admission. Education and information about clinical care were provided verbally to patients for 20 minutes. Data were collected from a post-survey completed on the day before the patients were discharged.

\subsection{Data Analyses}

Normality of the variables was assessed using the ShapiroWilks test. Normally distributed data were reported as means \pm Standard Deviations ( $S D \mathrm{~s})$, while non-normally distributed data were reported as both medians (range) and means $\pm S D$ s. Categorical data were reported using frequencies and percentiles. To test for differences in demographic character-istics, an independent two-sample t-test was performed on continuous data. For categorical data, a chi-squared test or Fisher's exact test was conducted, as appropriate. An analysis of covariance was used to determine intergroup differences in main outcomes, and using age, education, and pre-test scores as covariates for pre- and post-intervention effects. An independent two-sample t-test was used to determine differences in the prepost variables. The significance level was set at $p<.05$. All statistical analyses were performed using SPSS Statistics 23 (IBM, Armonk, NY, USA).

\subsection{Ethical Consideration}

This study was approved by the institutional review board (no. 2017-08-017) of Eulji University Hospital. Participants were informed of the objective and procedure of the study and of the guarantee that their personal information would remain private. We obtained informed, written consent from all participants after they received this information. Participants were instructed that, if their condition worsened or if they did not want to complete the surveys, the research would be terminated, and their data would be excluded from the final analyses.

\section{RESULTS}

\subsection{Demographic Characteristics and Homogeneity Test}

Participant's demographic and hospital-related characteristics are shown in Table $\mathbf{1}$. There were no differences between the treatment and control groups concerning age, sex, education, duration of operation, duration of anesthesia, etc. Additionally, after a homogeneity test of the dependent variables, it was confirmed that there were no differences between the two groups concerning anxiety, depression, uncertainty, and care satisfaction (Table 2).

\subsection{Analysis of the Main Outcomes of the Educational Program}

Participants' mean pre- and post-intervention anxiety, depression, uncertainty, and care satisfaction scores in both groups are shown in Table 3. Compared to the control group, patients in the treatment group displayed significantly decreased anxiety, depression, and uncertainty, as well as significantly increased care satisfaction.

\subsection{Subvariable Analysis of Uncertainty Regarding the Educational Program}

In addition to the main outcomes, the subvariables of uncertainty were analyzed. Comparing the treatment and control groups, the educational program proposed in this study significantly improved issues around ambiguity, complexity, and inconsistency, but not unpredictability (Table 4).

\section{DISCUSSION}

This study was performed to develop and implement a standardized care protocol for patients undergoing degenerative spinal surgery and to identify its impact on patient's anxiety, depression, uncertainty, and care satisfaction. We found that, after implementing our education-based program, these variables significantly changed in the treatment group in comparison to the control group.

Even before surgery, patients can feel anxious or depressed about the surgical process and the complications they may experience. Since anxiety and depression can have a negative effect on postoperative outcomes and rehabilitation, reducing anxiety and uncertainty in such patients is a vital medical issue [11]. Patients tend to feel anxious about not knowing what to expect; thus, timely and appropriate information should be provided for patients to understand and utilize [12, 13]. Therefore, we developed a standardized care protocol and applied it to spinal surgery patients. 
Table 4. Between-group comparisons of subvariables of uncertainty $(n=98)$.

\begin{tabular}{|c|c|c|c|c|c|}
\hline Category & Process & $\begin{array}{l}\text { Treatment group } \\
\quad(n=49)\end{array}$ & $\begin{array}{c}\text { Control group } \\
(n=49)\end{array}$ & $\begin{array}{c}\text { Test } \\
\text { statistic }\end{array}$ & $p$-value \\
\hline \multirow{3}{*}{ Ambiguity } & Pre & $47.31 \pm 4.29$ & $45.29 \pm 9.00$ & 1.324 & $.253^{\dagger}$ \\
\hline & Post & $29.78 \pm 6.09$ & $43.29 \pm 7.97$ & 224.93 & $<.001^{\ddagger}$ \\
\hline & Post-pre & $-17.53 \pm 6.02$ & $-2 \pm 3.98$ & 15.05 & $<.001$ \\
\hline \multirow{3}{*}{ Complexity } & Pre & $17.49 \pm 2.69$ & $16.47 \pm 2.64$ & 3.132 & $.08^{\dagger}$ \\
\hline & Post & $13.92 \pm 2.92$ & $16.14 \pm 2.53$ & 42.308 & $<.001^{\ddagger}$ \\
\hline & Post-pre & $-3.57 \pm 2.71$ & $-0.33 \pm 1.86$ & 6.88 & $<.001$ \\
\hline \multirow{3}{*}{ Inconsistency } & Pre & $20.06 \pm 2.16$ & $19.10 \pm 3.51$ & 1.92 & $.169^{\dagger}$ \\
\hline & Post & $15.18 \pm 3.44$ & $18.45 \pm 3.32$ & 54.969 & $<.001^{\ddagger}$ \\
\hline & Post-pre & $-4.88 \pm 3.32$ & $-0.65 \pm 1.96$ & 7.66 & $<.001$ \\
\hline \multirow{3}{*}{ Unpredictability } & Pre & $14.24 \pm 2.45$ & $14.61 \pm 2.79$ & 0.311 & $.578^{\dagger}$ \\
\hline & Post & $13.39 \pm 2.69$ & $14.08 \pm 2.28$ & 2.105 & $.15^{\ddagger}$ \\
\hline & Post-pre & $-0.86 \pm 2.44$ & $-0.53 \pm 1.4$ & 0.812 & $<.42$ \\
\hline
\end{tabular}

${ }^{7} p$-value based on an analysis of covariance with age and sex as covariates.

${ }^{\ddagger} p$-value based on an analysis of covariance with pre-test score, age, and sex as covariates.

This result was in consistent with a previous study's findings which demonstrated that anxiety and uncertainty were significantly reduced after participants completed an online education intervention, after undergoing cervical disc herniation surgery [11]. Another study examining patients with chest pain demonstrated that a clinical schedule positively influenced patient's length of stay and satisfaction; however, patient's anxiety was not significantly reduced post-intervention [34]. Another study addressing adult cancer patients showed that the clinical schedule could support cancer caring to assess and manage patient's anxiety and depression [35].

Pre-intervention, the mean anxiety scores of both the treatment and control groups were not within "normal" range (i.e., 0 to 7 [29]). Post-intervention, the mean anxiety score of the treatment group decreased to within normal range. The same was true for depression. Specifically, the treatment group showed a significant decrease in depression, compared to the control group, highlighting the clinical significance of this study.

Patients with spinal diseases experience depression and stress due to anxiety and uncertainty about the progression of their disease and aggravation of symptoms [36]. Anxiety influences clinical outcomes in lumbar spinal stenosis and degenerative spondylolisthesis patients [10]; therefore, alleviating anxiety and depression is critical. Medical staff should plan to provide patients with high-quality information regarding the surgery and side effects that can occur in the postsurgery period, before patients undergo surgery [7]. As patients' understanding can be improved by effective exchange of information between them and the medical staff, including surgeons and nurses [6], it is necessary to develop standardized guidelines to provide timely and accurate information to spinal surgery patients. It is noteworthy that our study of spinal disease patients focused on the entire hospitalization process, from admission to discharge, including the perioperative period.
We developed an efficient evidence-based care protocol, in contrast to the fragmented, discontinuous, and difficult to access care that patients may experience after discharge [37]. This protocol was designed to ensure that care and nursing schedules promote desirable clinical outcomes within the expected length of hospitalization and costs based on actual evidence and participant characteristics [38, 39]. Through the care protocol developed in this study, patients undergoing spinal surgery could engage in proper self-care.

Thus, the educational program was an effective intervention tool, perhaps because nurses could provide standardized treatment and care in explaining patients' planned treatment, examinations, and post-operative care, which, in turn, reduced patients' anxiety. Our results indicate a reduction in uncertainty and an increase in psychological stability; the easily accessible protocol helped patients avoid fear or anxiety about the effects of the examinations, surgery, and recovery period that they were about to face by allowing them to make predictions about the process and by increasing their compliance with the treatment through fluent communication and enhanced trust. The uncertainty felt by the patients in the treatment group significantly decreased in comparison to that of the patients in the control group. Of the four sub-areas of uncertainty, ambiguity, complexity, and inconsistency significantly differed between groups. This result could be considered significant, compared to that of a previous study examining patients undergoing cervical disc herniation surgery [11]. Moreover, the uncertainty score in this study was lower than the score found in a previous non-intervention study about patients with ankylosing spondylitis, while the uncertainty score was higher before treatment [40].

There was a significant change in patients' care satisfaction between the treatment and control groups before and after the intervention; however, the post-intervention satisfaction score in the treatment group was not high. This is probably because of a floor effect as patients' care satisfaction scores were low before the intervention. Nonetheless, a similar result was found 
in a previous study that examined patients with chest pain, albeit not the same disease [34].

The control group mainly received verbal explanations. Although the contents of education and information provision were the identical to both group, one concern might arise from that the provision of those to the control group was processed verbally without any assistance manual, so it was likely that different medical staffs might deliver it divergently. However, the treatment group was provided consistent information based on standardized care protocol. The care protocol was presented on the front page of a booklet, which was an integrated educational resource that contained a detailed explanation of the care protocol. Patient could utilize the care protocol that they could access repeatedly and easily as an educational learning tool. Moreover, patients could communicate with medical staff based on the care protocol and they were able to confirm and obtain valuable solutions on any questions. In this regard, it seems like these activities with a standardized care protocol were relevant in reducing treatment-group patients' anxiety, depression, and uncertainty, as well as increasing care satisfaction.

Providing standardized care, including setting specific criteria for care and treatment, examinations, a checklist for exercise planning/progress, simple visual educational materials, ensuring accurate nursing care for daily activities, and providing consistent communication between medical staff and patients resolved patients' concerns about the ambiguity, complexity, and inconsistency of medical procedures. Nurses reviewed and shared the treatment and nursing care plan with patients on a daily basis; the patients and nurses frequently engaged in question and answer sessions to avoid unpredictability. Consequently, it is considered that our results showed that the educational program based on the care protocol had a significant effect on clinical practice.

The pain felt after spinal surgery is severe even when patients do not experience complications [41]. Patients also experience discomfort because of their limited activity and must wear a brace to maintain spinal stability [20]. Explaining how patients can control destructive thoughts and avoid fear of pain can improve their recovery from mobility disorders and their quality of life [42]. This explanation can include simple visual materials on pain management such as controlled anesthesia and promoting activities of daily living and exercise. This preemptive pain management is thought to result in reduced anxiety and depression [12]. The main points of preemptive pain management included ignoring the pain intentionally, not concentrating on the pain, and focusing on things that bring happiness [12].

As depression and postoperative complications affect the length of spinal surgery patient's hospital stay, it is necessary to take systematic precautions before surgery [43]. Additionally, the need to shift to integrated care within the healthcare system has recently been emphasized. The standardized protocol developed in this study is a useful tool for multidisciplinary collaboration and effective education. It has often been suggested that consistently reproducing healthcare services is difficult, as they vary between producers, customers, locations, and times, and because distinct professionals (physicians, nurses, etc.) provide heterogeneous services to patients, who have a variety of demands. Experience, individual capacity, and personality lead to differences in the provision of services [44]. However, the quality of healthcare can be improved by factors such as supportive visionary leadership, proper planning, resource availability, effective management of resources, employees, and processes, and a cooperative environment [45]. Thus, an efficient standardized care protocol that defines the whole nursing process from admission to discharge and employs continuous, easy-toaccess, safe, and inexpensive approaches can be used to provide high-quality care to degenerative spinal surgery patients. It is also expected to contribute to improvements in patient's quality of life.

\section{CONCLUSION}

The results of this study suggest that the proposed care protocol has a positive effect on patient's anxiety, depression, uncertainty, and care satisfaction. Delivering accurate information to patients undergoing surgery for degenerative spine disease in a timely and proactive manner throughout their hospitalization appears to be effective. Using a standardized care protocol provides patients with high quality treatment and care services, helps them smoothly transition into the transient stage in their home settings after discharge, and can contribute to improving their quality of life.

The protocol in this study was developed by experts at a single university hospital setting. It must be verified and corroborated with multicenter studies to enhance the external validity of the current findings. Furthermore, the long-term effects of the protocol were not assessed. Criteria for evaluating the long-term effectiveness of the protocol should be developed and employed to assess the performance of the protocol against well-defined pre-set objectives.

\section{LIST OF ABBREVIATIONS}

$$
\begin{array}{ll}
\text { SD } & =\text { Standard Deviation } \\
\text { LOPSS } & =\text { La Monica-Oberst Patient Satisfaction Scale } \\
\text { MUIS } & =\text { Mishel Uncertainty in Illness Scale }
\end{array}
$$

\section{ETHICS APPROVAL AND CONSENT TO PARTICIPATE}

This study was approved by the institutional review board (no. 2017-08-017) of Eulji university hospital. All participants provided informed, written consent.

\section{HUMAN AND ANIMAL RIGHTS}

No Animals were used in this research. All human research procedures followed were in accordance with the ethical standards of the committee responsible for human experimentation (institutional and national), and with the Helsinki Declaration of 1975, as revised in 2013. 


\section{CONSENT FOR PUBLICATION}

Written informed consent was obtained from all the participants prior to publication.

\section{FUNDING}

This paper is supported by Eulji University, Daejeon, South Korea in 2017.

\section{CONFLICT OF INTEREST}

There are no conflicts of interest to declare. This paper was supported by Eulji University in 2017.

\section{ACKNOWLEDGEMENTS}

We are grateful to the patients who participated in this study. All authors have contributed to the design, analysis, and preparation of the study results.

Appendix A. Care Protocol for Spinal Surgery Patient During Hospitalization

\begin{tabular}{|c|c|c|c|c|c|c|c|}
\hline \multirow[t]{2}{*}{ Index } & \multirow{2}{*}{$\begin{array}{r}\text { Day before surgery } \\
\text { (day of admission) }\end{array}$} & \multicolumn{2}{|c|}{ Day of surgery } & \multirow{2}{*}{$\begin{array}{c}\text { 1-2 days } \\
\text { after surgery }\end{array}$} & \multirow{2}{*}{$\begin{array}{c}3-5 \text { days after } \\
\text { surgery }\end{array}$} & \multirow{2}{*}{$\begin{array}{l}\text { 6-7 days } \\
\text { after } \\
\text { surgery }\end{array}$} & \multirow{2}{*}{$\begin{array}{c}8 \text { days after surgery- } \\
\text { discharge }\end{array}$} \\
\hline & & Before surgery & After surgery & & & & \\
\hline $\begin{array}{l}\text { Care and } \\
\text { treatment }\end{array}$ & $\begin{array}{c}* \text { Measure } \\
\text { height/weight } \\
* \text { Secure } \\
\text { intravenous } \\
\text { injection } \\
\text { * Remove hair from } \\
\text { surgical area } \\
\text { * Fit brace }\end{array}$ & $\begin{array}{c}\text { * Remove jewelry } \\
\text { * Remove } \\
\text { dentures } \\
\text { * Remove } \\
\text { underwear } \\
\text { * Remove makeup } \\
\text { * Remove nail } \\
\text { polish } \\
\text { * Remove hearing } \\
\text { aids }\end{array}$ & $\begin{array}{c}\text { * Measure vital signs } \\
* \text { Observe surgical } \\
\text { wounds } \\
* \text { Measure/observe } \\
\text { total drainage amount } \\
\text { * Mediate pain } \\
\text { intervention }\end{array}$ & $\begin{array}{c}* \text { Possible to } \\
\text { remove urine } \\
\text { tube } \\
\text { * Possible to } \\
\text { remove } \\
\text { drainage tube } \\
\text { depending on } \\
\text { amount of } \\
\text { bleeding } \\
\text { * Simple } \\
\text { dressing }\end{array}$ & $\begin{array}{l}\text { * Possible to } \\
\text { remove } \\
\text { drainage tube } \\
\text { depending on } \\
\text { amount of } \\
\text { bleeding } \\
\text { * Simple } \\
\text { dressing }\end{array}$ & $\begin{array}{l}* \text { Simple } \\
\text { dressing }\end{array}$ & $\begin{array}{l}\text { * Simple dressing } \\
* \text { Remove the stitches }\end{array}$ \\
\hline Examination & $\begin{array}{c}\text { * Check whether } \\
\text { blood test and x-ray } \\
\text { were done at an } \\
\text { outpatient clinic }\end{array}$ & * Blood test & $\begin{array}{l}\text { * Move to the ward } \\
\text { after x-rays }\end{array}$ & & $\begin{array}{c}* \text { Blood test } \\
\text { (Monday, } \\
\text { Thursday) } \\
* \text { Take X-rays } \\
\text { (7 days and } 14 \\
\text { days after } \\
\text { surgery) }\end{array}$ & \begin{tabular}{|c|}
$*$ Blood test \\
(Monday, \\
Thursday) \\
$*$ Take X- \\
rays (7 days \\
and 14 days \\
after surgery)
\end{tabular} & \\
\hline Diet & $\begin{array}{c}* \text { Regular diet } \\
* \text { Fast after } \\
\text { midnight and do not } \\
\text { drink water }\end{array}$ & * Fasting & $\begin{array}{c}* 8 \text { hours after surgery } \\
\text { (after checking whether } \\
\text { diet is possible) } \\
\text { water/thin rice gruel } \\
\text { are okay }\end{array}$ & * Regular diet & * Regular diet & $\begin{array}{c}\text { * Regular } \\
\text { diet }\end{array}$ & * Regular diet \\
\hline Medication & $\begin{array}{l}* \text { Taking self- } \\
\text { medication } \\
\text { according to } \\
\text { directions }\end{array}$ & $\begin{array}{l}* \text { Taking self- } \\
\text { medication } \\
\text { according to } \\
\text { directions }\end{array}$ & $\begin{array}{c}* \text { Inject antibiotic } \\
\text { medication } \\
* \text { Inject cough and } \\
\text { phlegm medication } \\
* \text { Inject stomach- } \\
\text { protectant medication }\end{array}$ & $\begin{array}{l}* \text { Take oral } \\
\text { medication }\end{array}$ & $\begin{array}{c}* \text { Inject } \\
\text { antibiotic } \\
\text { medication } \\
* \text { Take oral } \\
\text { medication }\end{array}$ & $\begin{array}{c}* \text { Inject } \\
\text { antibiotic } \\
\text { medication } \\
* \text { Take oral } \\
\text { medication }\end{array}$ & $\begin{array}{l}* \text { Take oral } \\
\text { medication }\end{array}$ \\
\hline Activity & * Daily activity & $\begin{array}{l}\text { * Daily activity } \\
\text { and relaxation }\end{array}$ & * Bed rest & $\begin{array}{l}* \text { Bed rest } \\
* \text { Walking }\end{array}$ & * Walking & * Walking & * Walking \\
\hline $\begin{array}{c}\text { Education and } \\
\text { explanation }\end{array}$ & $\begin{array}{c}\text { * Care information } \\
\text { survey } \\
\text { * Instructions } \\
\text { during } \\
\text { hospitalization } \\
\text { * Various consent } \\
\text { (e.g. surgery, } \\
\text { anesthesia, etc.) } \\
\text { * Pulmonary } \\
\text { function test (if } \\
\text { needed), other } \\
\text { additional } \\
\text { examinations, etc. }\end{array}$ & $\begin{array}{c}* \text { Fasting } \\
\text { education } \\
* \text { Instructions } \\
\text { about moving to } \\
\text { the operating } \\
\text { room }\end{array}$ & $\begin{array}{c}\text { * Breathing and } \\
\text { coughing methods } \\
\text { * Expelling phlegm } \\
\text { * Preventing getting } \\
\text { hurt from falling } \\
\text { * Self-control methods } \\
\text { of pain } \\
\text { * Managing various } \\
\text { drainage tubes } \\
\text { * Diet education } \\
\text { * Preventing bedsores }\end{array}$ & $\begin{array}{c}* \text { How to } \\
\text { wear brace } \\
* \text { how to use } \\
\text { brace and } \\
\text { how to walk }\end{array}$ & $\begin{array}{c}* \text { How to wear } \\
\text { brace } \\
* \text { How to use } \\
\text { brace and how } \\
\text { to walk }\end{array}$ & & $\begin{array}{c}* \text { Precautions after } \\
\text { discharge } \\
* \text { Instructions about } \\
\text { making appointments } \\
\text { for follow-up visits } \\
* \text { Issue certificates as } \\
\text { needed } \\
\text { * Explanation on } \\
\text { discharge medication } \\
* \text { Education about } \\
\text { managing affected } \\
\text { areas }\end{array}$ \\
\hline $\begin{array}{l}\text { Date of } \\
\text { completion/ } \\
\text { signature }\end{array}$ & - & - & - & - & - & - & - \\
\hline
\end{tabular}

\section{Appendix B}

Complete booklet set
SUPPLEMENTARY MATERIAL

Supplementary material is available on the publishers Web 
site along with the published article.

\section{REFERENCES}

[1] Hey HW, Hee HT. Lumbar degenerative spinal deformity: Surgical options of PLIF, TLIF and MI-TLIF. Indian J Orthop 2010; 44(2): 159-62. Available from: http://www.ijoonline.com/text.asp?2010 /44/2/159/62066

[http://dx.doi.org/10.4103/0019-5413.62066] [PMID: 20419 002]

[2] Deyo RA, Gray DT, Kreuter W, Mirza S, Martin BI. United States trends in lumbar fusion surgery for degenerative conditions. Spine 2005; 30(12): 1441-5. Available from: https://insights. ovid.com/crossref?an=00007632-200506150-00016

[http://dx.doi.org/10.1097/01.brs.0000166503.37969.8a] [PMID: 159 59375]

[3] Francio VT, Towery C, Davani S, Brown T. Spinal manipulation and therapeutic exercises in treating post-surgical resurgent lumbar radiculopathy. Oxf Med Case Rep 2017; 186-90 Available from: https://academic.oup.com/omcr/article/2017/ 10/omx062/4508882 [http://dx.doi.org/10.1093/omcr/omx062]

[4] Health Insurance Review \& Assessment Service. 2014 [accessed Oct. 20, 2018]; Available from: http://www.hira.or.kr/bbsDummy.do? pgmid=HIRAA020041000100\&brdScnBltNo $=4 \&$ brdBltNo $=9054$

[5] Saban KL, Penckofer SM. Patient expectations of quality of life following lumbar spinal surgery. J Neurosci Nurs 2007; 39(3): 180-9. [http://dx.doi.org/10.1097/01376517-200706000-00009] [PMID: 175 91414]

[6] Hart RA, Cabalo A, Bess S, et al. Comparison of patient and surgeon perceptions of adverse events after adult spinal deformity surgery. Spine 2013; 38(9): 732-6. Available from: https://insights.ovid.com /crossref?an=00007632-201304200-00005

[http://dx.doi.org/10.1097/BRS.0b013e31827ae242] [PMID: 244770 53]

[7] Kurd MF, Lurie JD, Zhao W, et al. Predictors of treatment choice in lumbar spinal stenosis: A spine patient outcomes research trial study. Spine 2012; 37(19): 1702-7. Available from: https://insights.ovid.com/ crossref?an=00007632-201209010-00011

[http://dx.doi.org/10.1097/BRS.0b013e3182541955] [PMID: 22426 453]

[8] Maratos EC, Trivedi R, Richards H, Seeley H, Laing RJ. Psychological distress does not compromise outcome in spinal surgery. Br J Neurosurg 2012; 26(4): 466-71. Available from: https://www.tandfonline.com/doi/abs/10.3109/02688697.2011.644821 ?journalCode $=$ ibjn 20

[http://dx.doi.org/10.3109/02688697.2011.644821] [PMID: 22 248004]

[9] Kanaan SF, Yeh HW, Waitman RL, Burton DC, Arnold PM, Sharma NK. Predicting discharge placement and health care needs after lumbar spine laminectomy. J Allied Health 2014; 43(2): 88-97. [PMID: 24925036]

[10] Lee J, Kim HS, Shim KD, Park YS. The effect of anxiety, depression, and optimism on postoperative satisfaction and clinical outcomes in lumbar spinal stenosis and degenerative spondylolisthesis patients: cohort study. Clin Orthop Surg 2017; 9(2): 177-83. Available from: https://synapse.koreamed.org/

DOIx.php?id=10.4055/cios.2017.9.2.177.doi

[http://dx.doi.org/10.4055/cios.2017.9.2.177] [PMID: 28567 219]

[11] Chuang MF, Tung HH, Clinciu DL, et al. The effect of an integrated education model on anxiety and uncertainty in patients undergoing cervical disc herniation surgery. Comput Methods Programs Biomed 2016; 133: 17-23. Available from: https://linkinghub.elsevier.com/ retrieve/pii/S0169260715303692

[http://dx.doi.org/10.1016/j.cmpb.2016.05.003] [PMID: 2739 3796]

[12] Abyholm AS, Hjortdahl P. The pain takes hold of life. A qualitative study of how patients with chronic back pain experience and cope with their life situation. Tidsskr Nor Laegeforen 1999; 119(11): 1624-9. [PMID: 10385806]

[13] Abyholm AS, Hjortdahl P. Being believed is what counts. A qualitative study of experiences with the health service among patients with chronic back pain. Tidsskr Nor Laegeforen 1999; 119(11): 1630-2.

[PMID: 10385807]

[14] Kripalani S, Jackson AT, Schnipper JL, Coleman EA. Promoting effective transitions of care at hospital discharge: a review of key issues for hospitalists. J Hosp Med 2007; 2(5): 314-23. Available from: https://onlinelibrary.wiley.com/doi/full/10.1002/jhm.228 [http://dx.doi.org/10.1002/jhm.228] [PMID: 17935242]

[15] Jönsson B, Strömqvist B. Lumbar spine surgery in the elderly. Complications and surgical results. Spine 1994; 19(13): 1431-5. [http://dx.doi.org/10.1097/00007632-199407000-00001] [PMID: 7939970]

[16] Davis RE, Vincent C, Henley A, McGregor A. Exploring the care experience of patients undergoing spinal surgery: a qualitative study. $\mathrm{J}$ Eval Clin Pract 2013; 19: 132-8. Available from: https://online library.wiley.com/doi/abs/10.1111/j.1365-2753.2011.01783.x [http://dx.doi.org/10.1111/j.1365-2753.2011.01783.x]

[17] Ayyadhah Alanazi A. Reducing anxiety in preoperative patients: A systematic review. Br J Nurs 2014; 23(7): 387-93. Available from: https://www.magonlinelibrary.com/doi/full/10.12968/bjon.2014.23.7.3 87

[http://dx.doi.org/10.12968/bjon.2014.23.7.387] [PMID: 2473 2993]

[18] Harvey CV. Spinal surgery patient care. Orthop Nurs 2005; 24(6): 426-40.

[http://dx.doi.org/10.1097/00006416-200511000-00009] [PMID: 1631 9731]

[19] Abrashkin KA, Cho HJ, Torgalkar S, Markoff B. Improving transitions of care from hospital to home: what works? Mt Sinai J Med 2012; 79(5): 535-44. Available from: https://online library.wiley .com/doi/full/10.1002/msj.21332

[http://dx.doi.org/10.1002/msj.21332] [PMID: 22976359]

[20] Gruskay JA, Fu M, Bohl DD, Webb ML, Grauer JN. Factors affecting length of stay after elective posterior lumbar spine surgery: a multivariate analysis. Spine J 2015; 15(6): 1188-95. Available from: https://linkinghub.elsevier.com/retrieve/pii/S1529-9430(13)01617-3 [http://dx.doi.org/10.1016/j.spinee.2013.10.022] [PMID: 241 84639]

[21] Maureen PL. Nursing care of the patient undergoing lumbar spinal fusion. J Nurs Educ Pract 2018; 8: 44-53. Available from: http://www.sciedu.ca/journal/index.php/jnep/article/view/11751/7892 [http://dx.doi.org/10.5430/jnep.v8n5p44]

[22] Blackburn J, Madhavan P, Leung YL, Walburn M. An enhanced recovery program for elective spinal surgery patients. J Clin Outcomes Manag 2016; 23.

[23] Tarnanen S, Neva MH, Dekker J, et al. Randomized controlled trial of postoperative exercise rehabilitation program after lumbar spine fusion: study protocol. BMC Musculoskelet Disord 2012; 13: 123. Available from: https://bmcmusculoskeletdisord.biomedcentral.com /articles/10.1186/1471-2474-13-123

[http://dx.doi.org/10.1186/1471-2474-13-123] [PMID: 22817607]

[24] Harris JS. Development, use, and evaluation of clinical practice guidelines. J Occup Environ Med 1997; 39(1): 23-34. Available from: https://journals.lww.com/joem/Abstract/1997/01000/Development,_Us e, and Evaluation_of_Clinical.7.aspx

[http://dx.doi.org/10.1097/00043764-199701000-00007] [PMID: 9029 428]

[25] Lynn MR. Determination and quantification of content validity. Nurs Res 1986; 35(6): 382-5. Available from: https://insights. ovid.com/crossref?an=00006199-198611000-00017

[http://dx.doi.org/10.1097/00006199-198611000-00017] [PMID: 3640 358]

[26] Kang SW, Yoo JS, Ko IS. Development of a health information web site evaluation categories with items for diabetes mellitus. J Korean Soc Med Inform 2006; 11: 345-52.

[http://dx.doi.org/10.4258/jksmi.2005.11.4.345]

[27] Zigmond AS, Snaith RP. The hospital anxiety and depression scale. Acta Psychiatr Scand 1983; 67(6): 361-70. Available from: https://onlinelibrary.wiley.com/doi/abs/10.1111/j.1600-0447.1983.tb09 716.x

[http://dx.doi.org/10.1111/j.1600-0447.1983.tb09716.x] [PMID: 6880 820]

[28] Oh BJ, Lee EO, Tae YS, Um DC. Effects of a program to promote self-efficacy and hope on the self-care behavior and the quality of life in patients with Leukemia. J Korean Acad Nurs 1997; 27: 627-38.

[29] Snaith RP. The Hospital Anxiety and Depression Scale. Health Qual Life Outc 2003; 1(1): 29. Available from: https://hqlo. biomedcentral.com/articles/10.1186/1477-7525-1-29

[http://dx.doi.org/10.1186/1477-7525-1-29]

[30] Chung CW, Kim MJ, Rhee MH, Do HG. Functional status and psychosocial adjustment in gynecologic cancer patients receiving chemotherapy. Korean J Women Health Nurs 2005; 11: 58-66.

[31] Mishel MH. Uncertainty in illness. Image J Nurs Sch 1988; 20(4): 225-32. Available from: https://sigmapubs.onlinelibrary.wiley.com /doi/abs/10.1111/j.1547-5069.1988.tb00082.x [http://dx.doi.org/10.1111/j.1547-5069.1988.tb00082.x] [PMID: 3203 
947]

[32] Lim YH, Suh IS, Chung SH. Effects of surgery information service on one-day surgery patients' anxiety and satisfaction with nursing care. J Korean Acad Adult Nurs 2010; 22: 1-10.

[33] La Monica EL, Oberst MT, Madea AR, Wolf RM. Development of a patient satisfaction scale. Res Nurs Health 1986; 9(1): 43-50. [http://dx.doi.org/10.1002/nur.4770090108] [PMID: 3634418]

[34] Siebens K, Miljoen H, Fieuws S, Drew B, De Geest S, Vrints C. Implementation of the guidelines for the management of patients with chest pain through a critical pathway approach improves length of stay and patient satisfaction but not anxiety. Crit Pathw Cardiol 2010; 9(1): 30-4. Available from: https://journals.lww.com/critpathcardio/Abstract /2010/03000/Implementation_of_the_Guidelines_for_the.6.aspx [http://dx.doi.org/10.1097/HPC.0b013e3181d24549] [PMID: 20215 908]

[35] Butow P, Price MA, Shaw JM, et al. Clinical pathway for the screening, assessment and management of anxiety and depression in adult cancer patients: Australian guidelines. Psychooncology 2015; 24(9): 987-1001. Available from: https://onlinelibrary.wiley .com/doi/full/10.1002/pon.3920

[http://dx.doi.org/10.1002/pon.3920] [PMID: 26268799]

[36] Batmaz I, Sarıyıldız MA, Dilek B, Bez Y, Karakoç M, Çevik R. Sleep quality and associated factors in ankylosing spondylitis: relationship with disease parameters, psychological status and quality of life. Rheumatol Int 2013; 33(4): 1039-45. Available from: https://link.springer.com/article/10.1007\%2Fs00296-012-2513-2 [http://dx.doi.org/10.1007/s00296-012-2513-2] [PMID: 2294 0709]

[37] Boult C, Karm L, Groves C. Improving chronic care: the "guided care" model. Perm J 2008; 12(1): 50-4

[http://dx.doi.org/10.7812/TPP/07-014] [PMID: 21369513]

[38] De Bleser L, Depreitere R, De Waele K, Vanhaecht K, Vlayen J, Sermeus W. Defining pathways. J Nurs Manag 2006; 14(7): 553-63. Available from: https://onlinelibrary.wiley.com/ [http://dx.doi.org/10.1111/j.1365-2934.2006.00702.x] [PMID: 17004 966]

[39] Hewitt-Taylor J. Clinical guidelines and care protocols. Intensive Crit
Care Nurs 2004; 20(1): 45-52. Available from: https://www.science direct.com/science/article/pii/S0964339703000892?via\%3Dihub [http://dx.doi.org/10.1016/j.iccn.2003.08.002] [PMID: 1472 6253]

[40] Paik SI, Sohng KY. The effect of self-management course on pain, flexibility of lumbar spine, uncertainty and self-efficacy in patients with ankylosing spondylitis. J Muscle Joint Health 2003; 10: 156-66.

[41] Havakeshian S, Mannion AF. Negative beliefs and psychological disturbance in spine surgery patients: a cause or consequence of a poor treatment outcome? Eur Spine J 2013; 22(12): 2827-35. Available from: https://www.ncbi.nlm.nih.gov/pmc/articles/PMC3843780/pdf /586_2013_Article_2822.pdf

[http://dx.doi.org/10.1007/s00586-013-2822-5] [PMID: 236 95229]

[42] Monticone M, Ferrante S, Teli M, et al. Management of catastrophising and kinesiophobia improves rehabilitation after fusion for lumbar spondylolisthesis and stenosis. A randomised controlled trial. Eur Spine J 2014; 23(1): 87-95. Available from: https://www.ncbi.nlm.nih.gov/pmc/articles/PMC3897823/pdf/586 201 3_Article_2889.pdf

[http://dx.doi.org/10.1007/s00586-013-2889-z] [PMID: 238 36299]

[43] Armaghani SJ, Lee DS, Bible JE, et al. Increased preoperative narcotic use and its association with postoperative complications and length of hospital stay in patients undergoing spine surgery. Clin Spine Surg 2016; 29(2): E93-8. Available from: https://insights.ovid.com/crossref ?an $=01933606-201603000-00016$

[http://dx.doi.org/10.1097/BSD.0000000000000109] [PMID: 268899 98]

[44] Mosadeghrad AM. Towards a theory of quality management: an integration of strategic management, quality management and project management. Int $\mathrm{J}$ Modelling in Operations Manag 2012; 2(1): 89-117.

[http://dx.doi.org/10.1504/IJMOM.2012.043962]

[45] Mosadeghrad AM. Factors influencing healthcare service quality. Int J Health Policy Manag 2014; 3(2): 77-89. Available from: https://www.ncbi.nlm.nih.gov/pmc/articles/PMC4122083/pdf/IJHPM3-77.pdf

[http://dx.doi.org/10.15171/ijhpm.2014.65] [PMID: 25114946]

\section{(c) 2019 Lim and Kim.}

This is an open access article distributed under the terms of the Creative Commons Attribution 4.0 International Public License (CC-BY 4.0), a copy of which is available at: (https://creativecommons.org/licenses/by/4.0/legalcode). This license permits unrestricted use, distribution, and reproduction in any medium, provided the original author and source are credited. 